\title{
SiM
}

\section{The Art and Science of Targeted Grazing-A Producer's Perspective}

\author{
By Dan Macon, Flying Mule Farm
}

\section{On the Ground}

- Targeted grazing is an increasingly popular tool for managing vegetation over large landscapes.

- While the principles of targeted grazing are scientifically based, the successful practice of targeted grazing requires site-specific knowledge of plant growth, animal nutrition and grazing behavior, ecosystem function, and public relations.

- Targeted grazing requires significant producer investment-in livestock, infrastructure and equipment, and knowledge.

Keywords: targeted grazing, vegetation management, California rangelands.

Rangelands 36(5):31-35

doi: 10.2111/Rangelands-D-14-00028.1

c 2014 The Society for Range Management

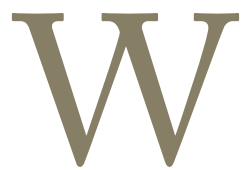

ith a population of nearly 60,000 people, the city of Rocklin in the western foothills of California's Placer County (east of Sacramento) barely recalls the small town where George Whitney and his son Parker decided to establish one of the largest sheep ranches in Gold Rush-era California. ${ }^{1}$ Today, the once oak-studded, rolling grasslands are covered by gated communities, golf courses - and a fair amount of county-mandated open space. But while the Parker Whitney Ranch is now the Whitney Oaks community and country club-home to 5,000+ people and nearly 2,000 homes-it is once again being grazed by sheep and goats. Indeed, in a 15mile corridor from Rocklin north to the city of Lincoln, more than 10,000 sheep and goats are used to manage vegetation in the late winter and early spring. Across much of urban and suburban California, municipalities, nonprofits, government agencies, and private landowners are turning to targeted grazing as a tool for managing rangeland landscapes.

\section{Targeted Grazing}

According to the Targeted Grazing Handbook, "targeted grazing is the application of a specific kind of livestock at a de- termined season, duration, frequency and intensity to accomplish defined vegetation or landscape goals." ${ }^{\text {A }}$ As the Annual Rangeland Handbook notes,

strategic application of increased stock density may be used to manage weed populations or reduce standing crop that competes with threatened or endangered species such as [plants associated with] vernal pools. Pastures containing critical habitat such as riparian areas or nesting habitat can be rested during critical periods and used at times that will not harm habitat. Resting pastures during restoration projects may facilitate plant establishment and reproduction. ${ }^{3}$

From a scientific perspective, as these references suggest, targeted grazing is straightforward. The appropriate species of livestock is placed on the rangelands to be managed at exactly the right time of year at exactly the right stocking rate for exactly the right duration. As with any real-world management system, however, the art of targeted grazing is much more complicated. Flying Mule Farm has provided targeted grazing services for small- to medium-sized (under 250 acres) projects in the Sierra foothills since 2008. We have also worked with several large targeted grazing contractors to manage large scale projects in the foothills and the Sacramento Valley. We have found that combining the scientific underpinnings of range science with the art of managing livestock, ecological processes, and human beings makes the business of targeted grazing uniquely challenging.

\section{Comparing Grazing to Other Treatments}

Many targeted grazing "customers" assume that grazing works similarly to other vegetation control methods-especially mowing or chemical application. From their perspective, the livestock are turned out, they graze all the plants to a specified level, and then are moved on to the next project. Spraying and mechanical treatments, however, often address the symptoms of lack of management or mismanagementin this respect, they are a short-term solution to a long-term problem. Grazing, if it's part of an overall plan, addresses this lack of management. This distinction is critical. The symptoms of no management-fuel-loading, invasive weed infes- 


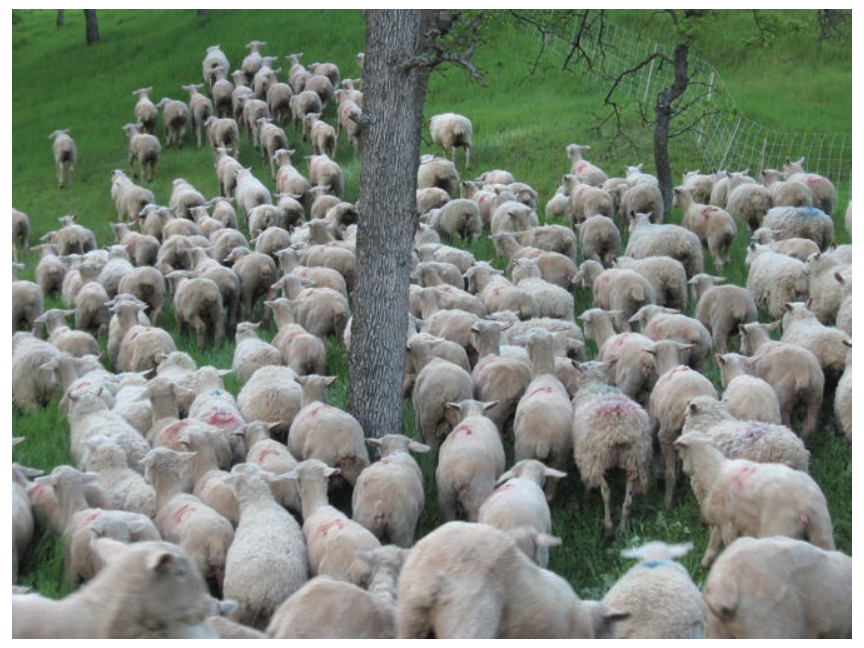

Figure 1. We have found that sheep are well-suited to managing annual vegetation in oak woodlands.

tations, reduction in ecological function-are generally not the result of one season, or even one year, of no management. Similarly, the disease cannot be "cured" in one season of targeted grazing. While spraying or mechanical treatments can be repeated in multiple years, some landscapes are too steep for machinery or too close to residential areas or other sensitive areas for chemical treatment. Similarly, burning might be a great option ecologically, but air quality and public safety concerns limit the use of fire in California. For example, I have found that controlling invasive Himalayan blackberries requires multiple grazing entries - the plants need to be "over-grazed" to the point where they are stressed enough to die. In some cases, this treatment may need to be repeated over several years. Furthermore, grazing involves three impacts (see below) — unlike mowing or spraying. Many clients are more familiar with the immediate gratification that comes with killing plants with herbicides or knocking them down with mowers. I find that I must explain this carefully and in the simplest terms when I'm talking to a client who doesn't have any background in rangeland management or livestock production.

\section{What's Your Business?}

Targeted grazing contractors must be clear with themselves (and with their clients) about the business they are in. Are they livestock producers who provide targeted grazing services? Are they land managers who use grazing animals as a tool for managing vegetation? My answers to these questions help me evaluate opportunities for targeted grazing. My primary business is sheep production. I offer targeted grazing services only when they complement the production needs of my animals. For example, I will not put my sheep onto targeted grazing projects in the 6 weeks prior to breeding-I use this time to improve their nutrition to increase conception rates and twinning percentages. If my primary business were vegetation management, on the other hand, I might run

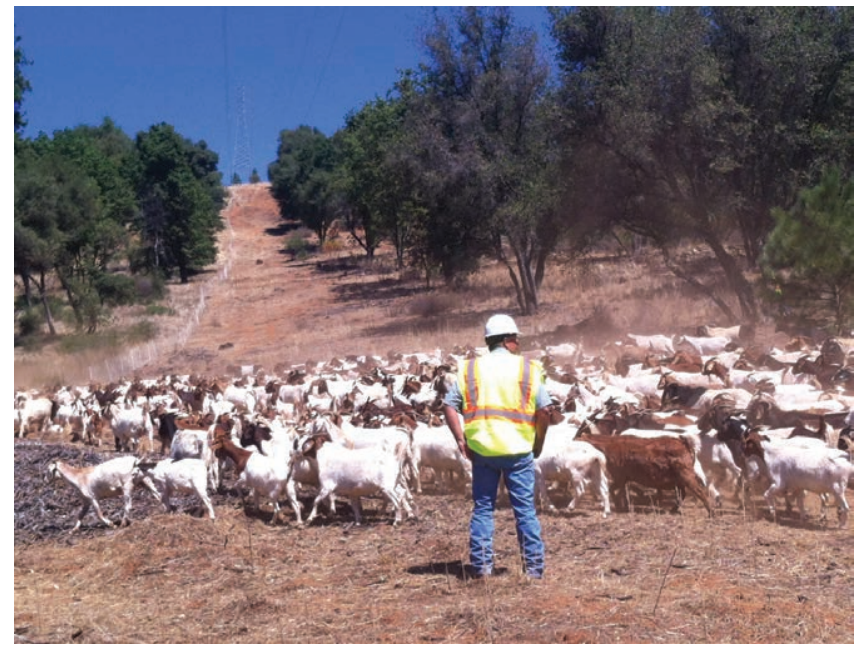

Figure 2. Goats are better suited to treating woody vegetation.

wether (castrated) goats and mature sheep with the understanding that I'm not trying to put weight on the animals. That said, every operation has classes of animals that can be pushed harder from a nutritional standpoint for a portion of the year. For example, we do not breed our replacement ewe lambs until they are fully grown (at 18 months of age). We often use these ewes in our targeted grazing projects because we can push their nutritional envelope.

\section{Matching Animals and Impacts to the Project}

Successful targeted grazing projects require a working understanding of vegetation, the environment and livestock impacts. I've found that the timing of my grazing projects depends on the goals of the client-if a landowner wants us to reduce fuel loads, we try to time our grazing to consume the fine fuels while minimizing the potential for regrowth. Other clients may want to reduce competition from nonnative grasses as part of an ecological restoration project. In this case, we try to time our grazing to impact the targeted plants-and time our rest period to allow native plants to flourish. We also differentiate between "grazing carbon" (that is, vegetation that our animals will graze) from "trample carbon" (usually dead standing material that we want to incorporate into the soil). Understanding livestock impactsgrazing, trampling and feces/urine deposition, as well as rest from these impacts—helps us design and manage successful targeted grazing projects.

We have found that different species and classes of animals often have different dietary preferences (and different impacts). Because we've established a flock of sheep that is exposed to a wide range of forages (from grasses to broad-leaf weeds to brush), our animals are able to utilize (and impact) widely varied types of vegetation. When we purchase sheep or goats that have not been "trained" to browse, for example, we find that we lose some productivity as these new animals adapt to our system. Dr. Fred Provenza's work has been especially helpful in this regard—understanding how animals 


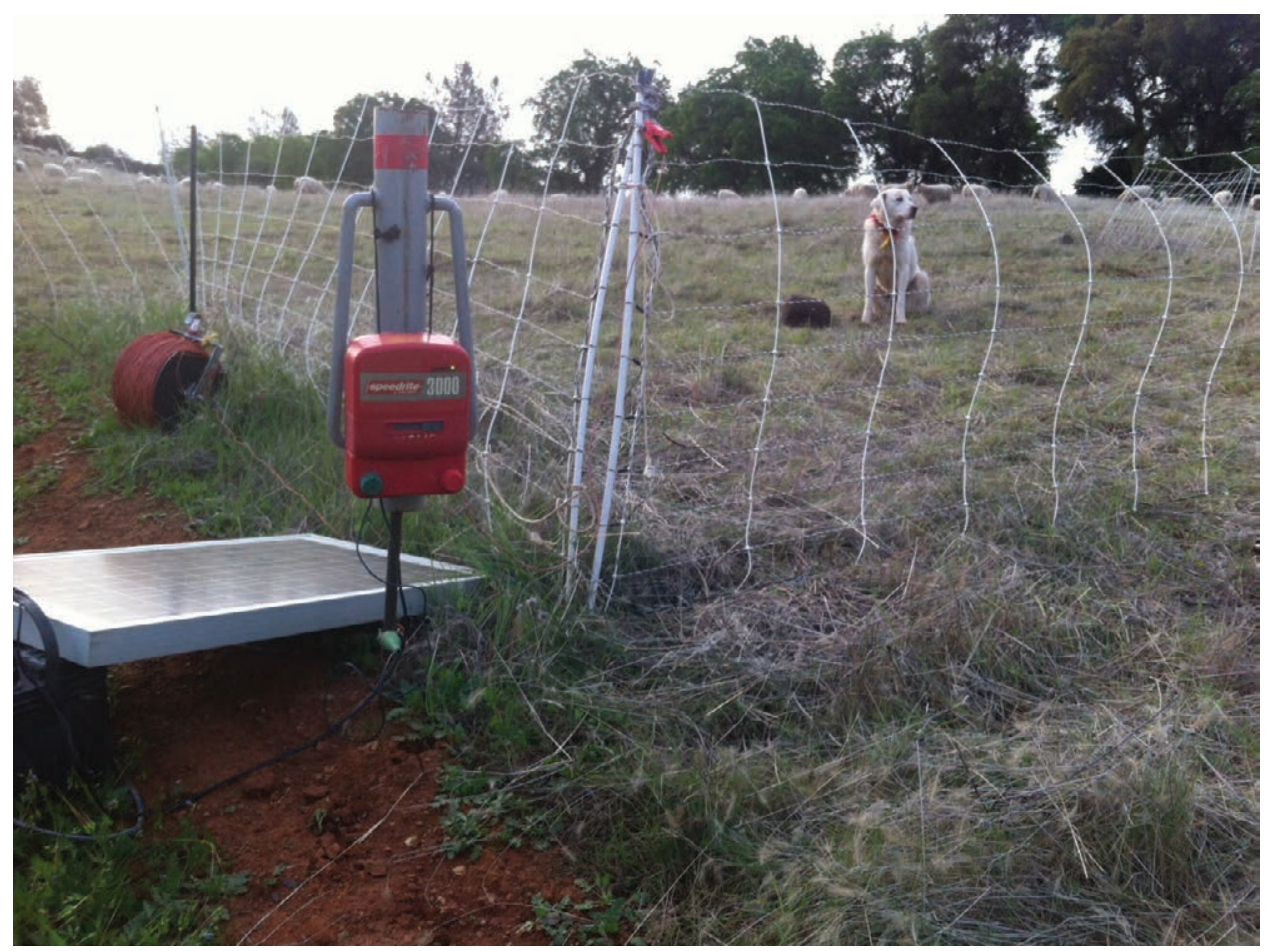

Figure 3. Electric fencing and predator protection are critical investments!

learn to graze is critical. For example, our lambs learn their dietary preferences from their mothers. Based on Dr. Provenza's work, we try to expose our sheep to a wide variety of vegetation while our lambs are still nursing so that they'll know how to graze this vegetation as adults. ${ }^{4}$

Finally, as the Targeted Grazing Handbook suggests, multispecies grazing can be beneficial in specific situations. ${ }^{2}$ We've used combinations of goats and sheep to tackle projects with a wide variety of vegetation types (from annual weeds to woody brush). (Figs. 1 and 2.) Cattle and horses may also have a place in targeted grazing systems-I've noticed that our mules will graze nasty annual grasses like barbed goat grass when our other livestock won't touch them. On the other hand, multispecies grazing can make projects more complicated. For example, goats require supplemental copper in their diets, while copper is toxic to sheep. In addition, I can load sheep into my trailer with nothing more than a good herding dog or two-I wouldn't try that technique with cattle (indeed, cattle generally require more equipment in my experience).

\section{Producer Investments}

Providing targeted grazing services requires livestock producers to make significant investments in infrastructure, livestock, knowledge and skills, and labor. We make extensive use of portable electric fencing systems (Fig. 3) and portable stock water systems - many of the projects we do are in areas with no fencing and limited access to stock water. In addition, we use livestock guardian dogs to protect our livestock from predators. We have also found it necessary to invest in developing our own knowledge and skills. We utilize border collies extensively to move livestock, load trailers, and perform other functions - and we've invested money and time in learning how to work with our dogs more effectively (Fig. 4). In many ways, learning to use dogs has had the greatest impact on our labor efficiency. We've invested in learning to identify plants, in how to estimate carrying capacity, and in mapping and estimating technology. Most importantly, we've built relationships with other targeted grazing contractors to allow us to mobilize larger numbers of livestock than any of us can access independently. We've also invested in skills and technology that make our labor more efficient. Fence-building is the most labor-intensive part of most projects-doubling my fence building efficiency cuts my labor costs in half.

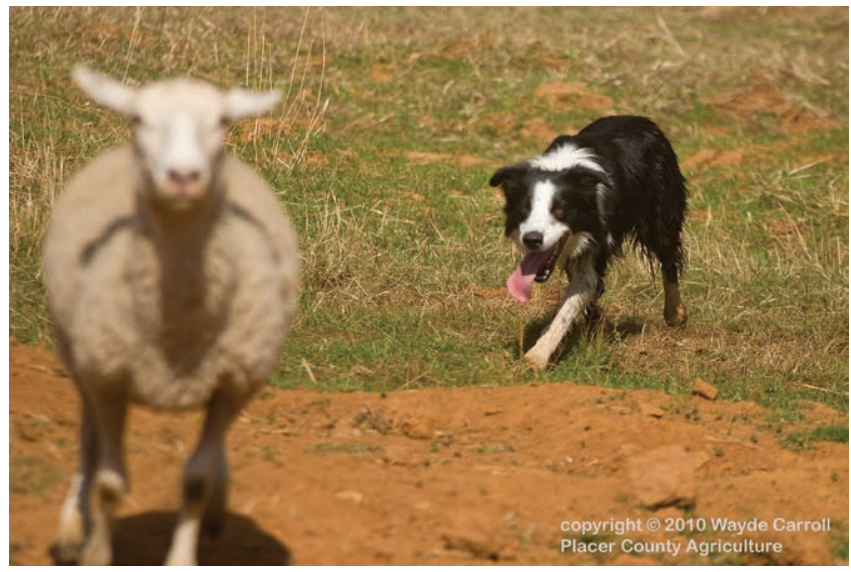

Figure 4. Well-trained herding dogs make my life much easier! 
This brings us to the importance of scale. To optimize animal impact and to treat as many acres per day as possible, targeted grazing requires high stock density, large numbers of animals, and frequent moves. On a recent project we completed for Pacific Gas and Electric, we found that 900 goats could treat 4 acres per day. From an economic standpoint, this many animals allowed us to keep our per acre charge in line with other vegetation management options (like mechanical or chemical treatment). From a labor standpoint, we find it takes almost as much labor to manage and move 300 goats as it takes to handle 900 animals. Table 1 compares the costs of treating another project in 2009 and 2010 with different numbers of animals. The economic feasibility of a specific targeted grazing project is directly related to scale.

\section{Risks}

Targeted grazing is not without its risks-both for the livestock operator and for the land manager. When we are managing projects in urban or suburban areas, we are concerned with vandalism and theft. We've had electric fence energizers and solar panels stolen, fence posts broken, and livestock chased through fences (by children and by dogs). When this happens, we also have the risk of livestock injury (if they get onto roadways) and property damage. We pay close attention to the potential for toxic plants-landscaping plants and natural toxic plants both pose a problem. Obviously, learning to identify common toxic plants is critical, as is recognizing symptoms of poisoning. I've found that the best resource in the field is the Cornell University poisonous plants website. ${ }^{5}$ Predators can also be a risk. While most people think of mountain lions and coyotes as the primary predator threat, our biggest problems have been with domestic dogs. We find that the combination of electric fence and livestock guardian dogs reduce the predator risk to an acceptable level. While we've found that most invasive weed seeds do not seem to survive a trip through a sheep's or goat's digestive system, we do worry about transporting weed seeds on our fencing and equipment. We clean our equipment before moving to another site. Finally, we are concerned about wildfire in or adjacent to our grazing projects. We carry fire tools and water during the fire season, and we try to plan for at least two escape routes for our animals in the event of fire.

\section{Public Relations}

Public relations is a time-consuming but necessary part of targeted grazing. In an era where most people no longer have direct experience working with livestock, goats and sheep are a curiosity. I find that I spend much of my time answering questions about grazing, electric fencing, animal behavior, and other topics that I take for granted. A mob of goats or a band of sheep within an urban area is always newsworthy, and I've realized that I've needed to learn how to talk to the news media as well. In many respects, social media (especially Facebook) has become a useful tool for educating the public about targeted grazing projects.

\section{Conclusions}

As the factors above suggest, targeted grazing takes a high level of planning and management skill. Coordinating schedules, transportation, labor, equipment movement, public

Table 1. A comparison of costs incurred while treating the same property with different stocking rates

\begin{tabular}{|l|c|c|}
\hline & $\mathbf{2 0 0 9}$ Canyonview project & $\mathbf{2 0 1 0}$ Canyonview project \\
\hline Stocking rate/class of livestock & 67 ewes, 13 mature goats & 211 ewes \\
\hline Acreage treated & 7.5 acres & 10 acres \\
\hline Project duration & 40 days & 21 days \\
\hline \# of gooseneck trailer loads & 3 & 6 \\
\hline Transportation hours (move-in and move-out) & 10 hours & 20 hours \\
\hline Labor (hours) & 58 hours & 64 hours \\
\hline Gross revenue & $\$ 3,200$ & $\$ 4,400$ \\
\hline Return to labor & $\$ 38.10 / \mathrm{hour}$ & $\$ 64.70 / \mathrm{hour}$ \\
\hline Cost per treated acre & $\$ 426$ & $\$ 440$ \\
\hline
\end{tabular}


relations, animal health, and grazing management are timeconsuming and complicated components of this work. In California's annual rangelands, we tend to have a 75-day window where goats and sheep are in very high demand-the trick is determining where these animals will spend the rest of the year. We joke that we need 10,000 head of sheep and goats in our region of the Sierra foothills in March and April, but we only need 500 the rest of the year! Many operations are recreating the historic transhumance system of moving livestock to better forage as the seasons progress (either to higher elevations or to more northerly latitudes). For example, the sheep and goats that we manage in the springtime move to mountain pastures in the Sierra or even in Idaho and Montana during the summer.

While most of us who provide targeted grazing services apply current rangeland research in our day-to-day management, there are some new research needs specific to this type of work. I believe there is also a need to apply more rigorous, science-based monitoring to targeted grazing projects, especially with respect to long-term trends in vegetative composition and rangeland health. While some research has been done on the nutritional value of brush species in California, I believe we need more information about seasonal variation in the nutritional value of brush and invasive annual plants. We also need a better understanding of secondary compounds and potential toxicity in brush and invasives. This would allow targeted grazing operators to design nutritional supplementation and grazing management strategies that address both vegetation and animal health needs. I also feel that we need more information on how to implement targeted grazing strategies after wildfire has occurred. Properly managed targeted grazing might help speed fire recovery efforts, but we need better knowledge in this area. Finally, I believe we need more research into how to use other livestock species (especially cattle and horses) to achieve specific targeted grazing goals. Much of the focus to date, especially on the part of targeted grazing operators, has been on small ruminants (sheep and goats). Other grazing animals probably have specific niches they would fill, but we need more information about what these niches might be.
Targeted grazing can provide an opportunity for livestock producers to diversify their revenue streams and expand their operations. Like any business opportunity, however, targeted grazing comes with its own specific risks and costs. And like any human interaction with the environment, targeted grazing requires a thoughtful combination of art and science. Greater collaboration between producers and the scientific community can only help make targeted grazing an even more useful tool for managing landscapes in California and elsewhere.

\section{References}

1. Day, G. 2011. Wool found in Whitney Ranch's Origins. The Placer Herald. Available at: http://www.placerherald.com/article/ wool-found-whitney-ranchs-origins. Accessed 30 July 2014.

2. Launchbaugh, K., and J. Walker. 2006. Chapter 1. Targeted grazing - a new paradigm for livestock management. Targeted grazing handbook, American sheep industry. Available at: http://www.sheepusa.org/researcheducation_ literature_targetedgrazing. Accessed 30 July 2014.

3. George, M., B. Frost, and N. McDougald. 2014. Chapter 8. Grazing management. Annual rangeland handbook. Available at: http://californiarangeland.ucdavis.edu/Annual_ Rangeland_Handbook/Grazing_Management_322/. Accessed 30 July 2014.

4. Howery, L. D., F. D. Provenza, and B. Burrit. 2010. Herbivores learn to forage in a world where the only constant is change. University of Arizona Cooperative Extension Publication AZ1518. Available at: http://extension.arizona.edu/sites/ extension.arizona.edu/files/pubs/az1518.pdf. Accessed 30 July 2014.

5. Brown, D. 2014. Plants poisonous to livestock and other animals. Cornell University, Department of Animal Science. Available at: http://www.ansci.cornell.edu/plants/. Accessed 30 July 2014.

Author owns Flying Mule Farm, a small commercial sheep operation in the Sierra Nevada footbills. Flying Mule Farm produces grass-fed lamb, mutton, and fiber products and provides targeted grazing services for a variety of clients. Auburn, CA 95602, USA, flyingmulefarm@gmail.com. 